\title{
Clouds-Aerosols-Precipitation Satellite Analysis Tool (CAPSAT)
}

\author{
I. M. Lensky ${ }^{1}$ and D. Rosenfeld ${ }^{2}$ \\ ${ }^{1}$ Department of Geography and Environment, Bar-Ilan University, Ramat-Gan, Israel \\ ${ }^{2}$ Institute of Earth Sciences, The Hebrew University of Jerusalem, Jerusalem, Israel
}

Received: 13 November 2007 - Published in Atmos. Chem. Phys. Discuss.: 5 March 2008

Revised: 15 September 2008 - Accepted: 29 September 2008 - Published: 24 November 2008

\begin{abstract}
A methodology for representing much of the physical information content of the METEOSAT Second Generation (MSG) geostationary satellite using red-greenblue (RGB) composites of the computed physical values of the picture elements is presented. The physical values are the solar reflectance in the solar channels and brightness temperature in the thermal channels. The main RGB compositions are (1) "Day Natural Colors", presenting vegetation in green, bare surface in brown, sea surface in black, water clouds as white, ice as magenta; (2) "Day Microphysical", presenting cloud microstructure using the solar reflectance component of the $3.9 \mu \mathrm{m}$, visible and thermal IR channels; (3) "Night Microphysical", also presenting clouds microstructure using the brightness temperature differences between 10.8 and $3.9 \mu \mathrm{m}$; (4) "Day and Night", using only thermal channels for presenting surface and cloud properties, desert dust and volcanic emissions; (5) "Air Mass", presenting mid and upper tropospheric features using thermal water vapor and ozone channels. The scientific basis for these rendering schemes is provided, with examples for the applications. The expanding use of these rendering schemes requires their proper documentation and setting as standards, which is the main objective of this publication.
\end{abstract}

\section{Introduction}

Satellite observations play a key role in understanding cloudaerosol climate effects. Now with multi channel geostationary satellites there are many new ways to gain additional insights. Rosenfeld and Lensky (1998) introduced a technique to investigate precipitation formation processes using "snap shot" from the Advanced Very High Resolution Radiometer

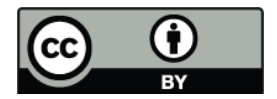

Correspondence to: I. M. Lensky (lenskyi@mail.biu.ac.il)
(AVHRR) data on the polar orbiting NOAA satellites. This technique uses both qualitative and quantitative approaches to understanding precipitation forming processes. For the qualitative approach, they used an RGB display of the NOAA AVHRR channel data that highlights the cloud microphysics, i.e. particle size and temperature for inferring phase (water/ice). For the quantitative approach they used the vertical profiles of the effective radius of cloud particles. Lensky and Rosenfeld (2003a) expanded their technique to gain insights into precipitation forming processes at nighttime and proposed an algorithm to delineate rain at nighttime using these insights (Lensky and Rosenfeld, 2003b).

The Rosenfeld Lensky Technique (RLT) was applied later to other sensors on polar orbiting satellites (VIRS on TRMM, GLI on ADEOS II, MODIS on Terra and Aqua), and was used in many studies to assess the impact of different aerosols on clouds and precipitation. (Rosenfeld, 1999, 2000; Rosenfeld et al., 2001, 2002, 2004, 2007; Rosenfeld and Woodley, 2001, 2003; Ramanathan et al., 2001; Rudich et al., 2002, 2003; Tupper et al., 2004; Williams et al., 2002; Woodley et al., 2000; Lensky and Drori, 2007; From et al., 2006; Martins et al., 2007).

The quantitative part of the RLT is based on two assumptions:

1. The evolution of cloud top effective radius $\left(r_{e}\right)$ with height (or cloud top temperature, $T$ ), observed by the satellite at a given time (snapshot) for a cloud ensemble over an area, is similar to the $T-r_{e}$ time evolution of a given cloud at one location. This is the ergodicity assumption, which means exchangeability between the time and space domains.

2. The $r_{e}$ near cloud top is similar to that well within the cloud at the same height as long as precipitation does not fall through that cloud volume.

The second assumption was verified using in situ aircraft measurements (Rosenfeld and Lensky, 1998; Freud et al.,

Published by Copernicus Publications on behalf of the European Geosciences Union. 

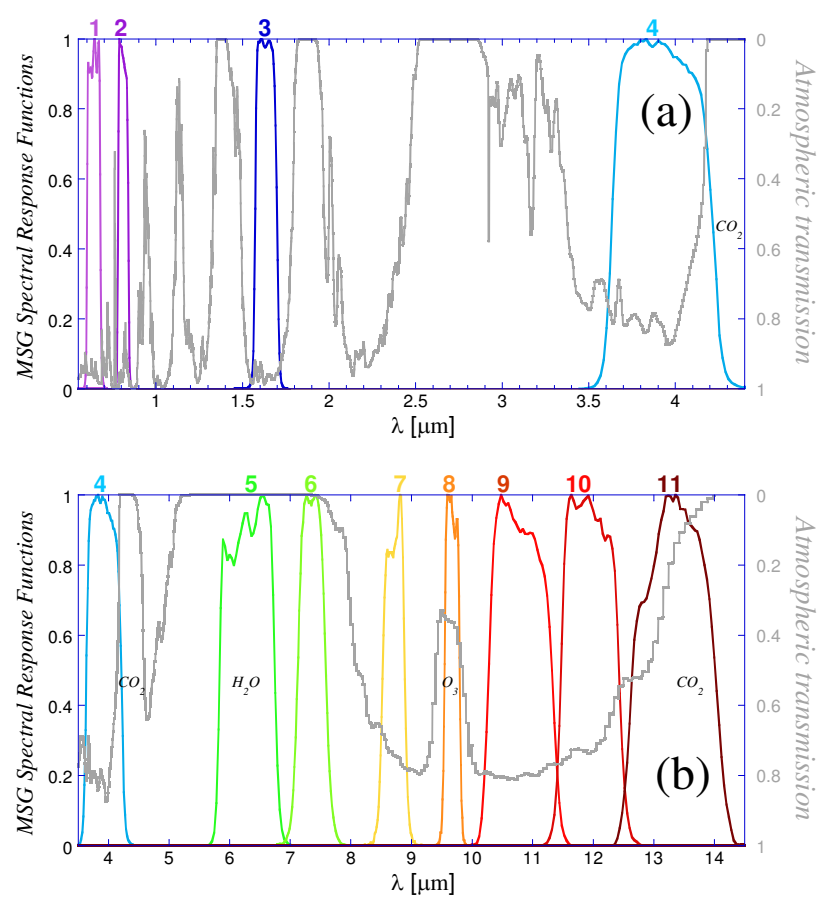

Fig. 1. MSG spectral response functions are shown (channel number on top of the curves) together with the atmospheric transmission curve (gray). Few absorbing molecules responsible for low atmospheric transmission are also shown. (a) Solar channels, (b) thermal channels.

2008). To address the ergodicity assumption (the first assumption), Lensky and Rosenfeld (2006) used rapid scan data (three minutes interval) of the Spinning Enhanced Visible and InfraRed Imager (SEVIRI) on board METEOSAT Second Generation (MSG) - the European geostationary satellite operated by EUMETSAT. A compete overview of the MSG SEVIRI instrument is provided by Schmetz et al. (2002). One outcome of this study evolved into a tool for cloud microphysical characterization and aerosol-cloud interaction detection. The rich spectral information of the SEVIRI instrument was used to expand both the qualitative and the quantitative parts of the RLT. We gave this tool the name CAPSAT: Clouds-Aerosols-Precipitation Satellite Analysis Tool. At present CAPSAT reads MSG SEVIRI data, we plan to expand its ability to read other meteorological satellite data.

With the rich spectral information of the SEVIRI instrument on the MSG satellite, we review and update the new capabilities of the RLT qualitative approach. In a subsequent publication we will do the same for the quantitative approach.

\section{Display - the qualitative approach}

As in the RLT, we display the physical quantities: reflectance [\%] in the solar channels, and brightness temperature (BT) $[\mathrm{K}]$ in the thermal channels. At daytime the radiation measured in MSG channel $4(3.9 \mu \mathrm{m})$ has both reflected solar radiation and emitted thermal radiation, therefore we allow the display of the solar reflectance or the BT of the total radiation measured by the sensor. Another "complication" with this channel is the $\mathrm{CO}_{2}$ absorption. The spectral band of MSG channel 4 has been broadened to longer wavelengths to improve signal-to-noise ratio (Schmetz et al., 2002) resulting in an overlap between the $\mathrm{CO}_{2}$ absorption band and the channel 4 response function (Fig. 1a). We suggest an algorithm to "correct" for the cooling of the BT measured in the $3.9 \mu \mathrm{m}$ channel due to the $\mathrm{CO}_{2}$ absorption. The correction uses BT from a window channel $(10.8 \mu \mathrm{m})$ and the $\mathrm{CO}_{2}$ absorption band of $13.4 \mu \mathrm{m}$ (see Fig. 1b). All the technical details can be found in Appendix A - Data preparation. Appendix B discusses enhancement of the high/low ( $\Gamma$ enhancement) or middle/high and low ( $\Gamma_{2}$ enhancement) parts of the selected intensity range.

As mentioned in the introduction, the RLT used a meaningful RGB combination for a qualitative analysis of the cloud microphysics. The 11 bands spectral information of the MSG is much richer then that of the five AVHRR bands that was used in the RLT, therefore CAPSAT can offer many more meaningful RGB combinations. The eight MSG thermal IR channels (channel 4 is both thermal and solar) are shown in Fig. 1b. Channels 4, 7, 9 and 10 are considered window channels. Figure 2 shows results of Santa Barbara DISORT Atmospheric Radiative Transfer (SBDART) calculations (Ricchiazzi et al., 1998) for optically deep clouds $(\tau=200)$ with their cloud tops at $5 \mathrm{~km}$, and a sensor located at cloud top. The radiance of seven clouds with particle effective radius of: 5, 10, 20, 30, 40, 50 and $106 \mu$ m were calculated for wavelengths between 3 and $14 \mu \mathrm{m}$. The inverse Planck function was used to calculate the BT of the different clouds at all wavelengths, and the highest BT was assumed to be the cloud top temperature $T$. The emissivity $(\mathrm{BT} / \mathrm{T})^{4}$ is plotted in Fig. 2 for the seven clouds, together with the atmospheric transmission (in gray) and horizontal bars representing the MSG thermal channels. It is clear from Fig. 2 that channel 4 is most sensitive to particle size, followed by channel 7.

CAPSAT (available from: http://home.geoenv.biu.ac.il/ page.php?num=46) offers control over treatment of channel 4 (solar and thermal contributions; $\mathrm{CO}_{2}$ absorption), use of pre-defined color schemes, gamma corrections of each of the RGB beams. It also provides quantitative analysis capabilities such as: cloud mask and retrieval of microphysical zones (Rosenfeld and Lensky, 1998) which will be provided in a later publication. 


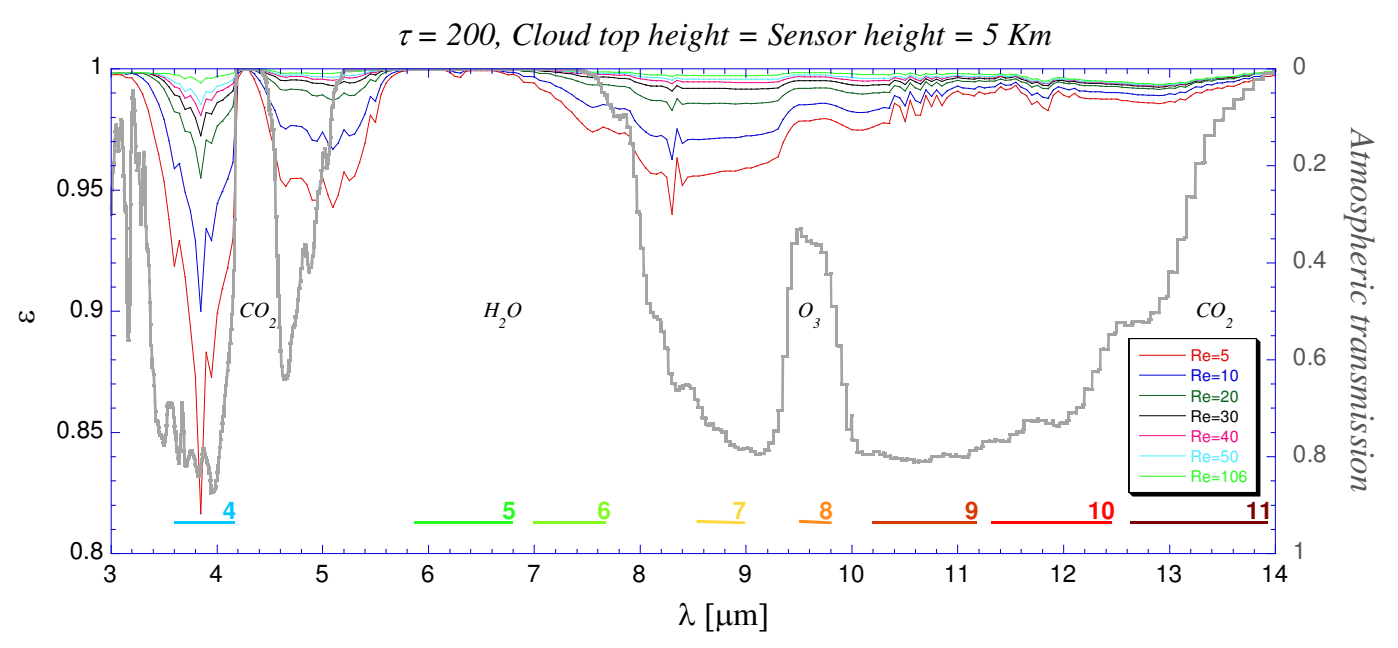

Fig. 2. The water cloud emissivity calculated from radiative transfer model for optically deep clouds $(\tau=200)$ with cloud tops at $5 \mathrm{~km}$ and varying effective radii. The sensor is located at cloud top. The colored horizontal bars represent the MSG thermal channels. The Atmospheric transmission is displayed in gray.

In the next sections we will discuss some predefined color schemes that were officially adopted by the EUMETSAT MSG interpretation guide (http://oiswww.eumetsat.org/ WEBOPS/msg_interpretation/index.html). There are seven pre-defined color schemes, with small variations on two of them. The first four color schemes use solar reflectance data from one or more of the four MSG solar channels. Obviously these color schemes can be used only in daytime. The other three color schemes can be used at nighttime, two of them use only thermal channels (MSG channel 4 has a solar component at daytime) and can be used at daytime as well. The full description of the parameters that define these color schemes can be found in Table 1 .

\section{Color schemes using solar reflectance}

\subsection{Day natural colors}

Figure 3 shows an RGB composition of the "Day Natural Colors" color scheme: $1.6,0.8$, and $0.6 \mu \mathrm{m}$ reflectance in the red green and blue beams, respectively. Figure 4 shows the spectral response functions of the three channels of the "Day Natural Colors" color scheme and spectral signatures of several surface types. In this color scheme vegetation appears greenish (A) because of its large reflectance in $0.8 \mu \mathrm{m}$ (the green beam) compared to $1.6 \mu \mathrm{m}$ (red beam) and to $0.6 \mu \mathrm{m}$ (blue beam). Water clouds with small droplets (C) have large reflectance at all three bands and hence appear whitish, while snow (F) and ice clouds (D) appears cyan because ice strongly absorbs in $1.6 \mu \mathrm{m}$ (no red). Bare ground (I) appears brown because of the larger reflectance in the $1.6 \mu \mathrm{m}$ than at $0.8 \mu \mathrm{m}$, and the ocean $(\mathrm{J})$ appears black because of the low reflectance in all three bands.

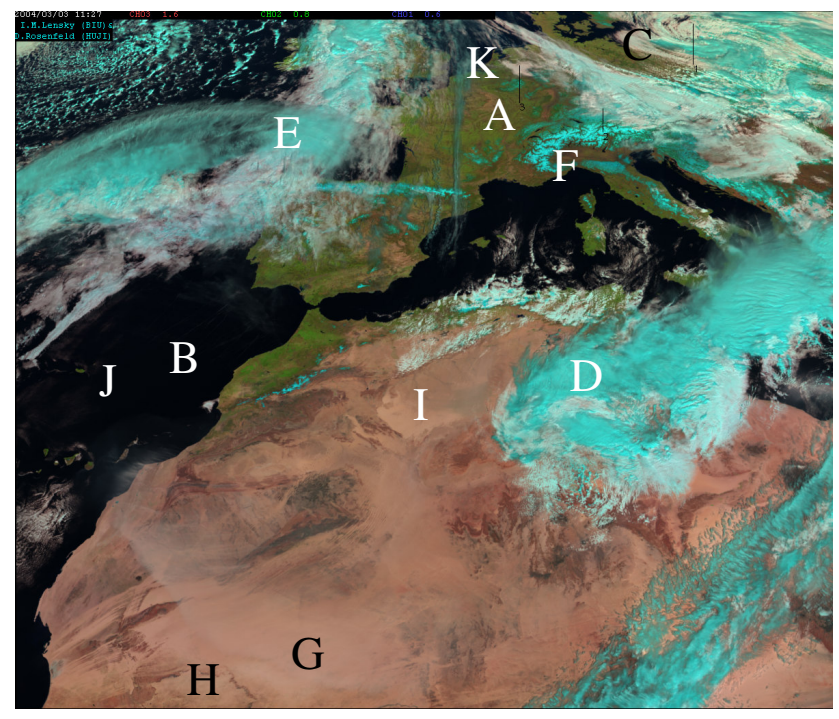

Fig. 3. RGB composition of the "Day Natural Colors" color scheme: $1.6,0.8$, and $0.6 \mu \mathrm{m}$ reflectance in the red green and blue beams respectively from 3 March 2004, 11:27 UTC.

The "Day Natural Colors Enhanced" (Fig. 5) is the same as the "Day Natural Colors" color scheme, only $\Gamma=3$ is used to stretch all the three beams (see Appendix B). This color scheme is useful for detecting dust (L), other kinds of aerosols and very thin clouds and contrails (B) over the sea. Typical values and the resulting colors are given in Table 2 .

\subsection{Day microphysical}

The RGB composition for the "Day Microphysical" color scheme (Fig. 6) was inherited from Rosenfeld and Lensky 
Table 1. Parameters for the predefined color schemes.

\begin{tabular}{|c|c|c|c|c|c|c|c|c|c|c|c|c|}
\hline \multirow{2}{*}{ Color scheme } & \multicolumn{4}{|c|}{ Red } & \multicolumn{4}{|c|}{ Green } & \multicolumn{4}{|c|}{ Blue } \\
\hline & Channel & Min & Max & Stretch & Channel & Min & Max & Stretch & Channel & Min & $\operatorname{Max}$ & Stretch \\
\hline $\begin{array}{l}\text { Day Natural } \\
\text { Colors }\end{array}$ & NIR1.6 & $0 \%$ & $100 \%$ & Linear & VIS0.8 & $0 \%$ & $100 \%$ & Linear & VIS0.6 & $0 \%$ & 100 & Linear \\
\hline $\begin{array}{lr}\text { Day } & \text { Natu- } \\
\text { ral } & \text { Colors }\end{array}$ & & & & $\Gamma=3$ & & & & $\Gamma=3$ & & & & $\Gamma=3$ \\
\hline \multicolumn{13}{|l|}{ Enhanced } \\
\hline $\begin{array}{l}\text { Day Micro- } \\
\text { physical }\end{array}$ & VIS0.8 & $0 \%$ & $100 \%$ & Linear & IR3.9r & $0 \%$ & $60 \%$ & $\Gamma=2.5$ & IR10.8 & $203 \mathrm{~K}$ & $323 \mathrm{~K}$ & Linear \\
\hline Day Solar & VIS0.8 & $0 \%$ & $100 \%$ & $\Gamma=1.7$ & NIR1.6 & $0 \%$ & $70 \%$ & $\Gamma=1.7$ & IR3.9r & $0 \%$ & $60 \%$ & $\Gamma=2.5$ \\
\hline $\begin{array}{l}\text { Convective } \\
\text { Storms }\end{array}$ & $\begin{array}{l}\text { WV6.2- } \\
\text { WV7.3 }\end{array}$ & $-30 \mathrm{~K}$ & $0 \mathrm{~K}$ & Linear & IR3.9-IR10.8 & $0 \mathrm{~K}$ & $55 \mathrm{~K}$ & $\Gamma=0.5$ & NIR1.6-VIS0.6 & $-70 \%$ & $20 \%$ & Linear \\
\hline $\begin{array}{l}\text { Night Micro- } \\
\text { physical }\end{array}$ & $\begin{array}{l}\text { IR12.0- } \\
\text { IR10.8 }\end{array}$ & $-4 \mathrm{~K}$ & $2 \mathrm{~K}$ & Linear & IR10.8-IR3.9 & $0 \mathrm{~K}$ & $6 \mathrm{~K}$ & $\Gamma=2$ & IR10.8 & $243 \mathrm{~K}$ & $293 \mathrm{~K}$ & Linear \\
\hline $\begin{array}{l}\text { Day and } \\
\text { Night }\end{array}$ & $\begin{array}{l}\text { IR12.0- } \\
\text { IR10.8 }\end{array}$ & $-4 \mathrm{~K}$ & $2 \mathrm{~K}$ & Linear & IR10.8-IR8.7 & $0 \mathrm{~K}$ & $6 \mathrm{~K}$ & $\Gamma=1.2$ & IR10.8 & $248 \mathrm{~K}$ & $303 \mathrm{~K}$ & Linear \\
\hline Desert Dust & & & & & & & $15 \mathrm{~K}$ & $\Gamma=2.5$ & & $261 \mathrm{~K}$ & $289 \mathrm{~K}$ & \\
\hline Air Mass & $\begin{array}{l}\text { WV6.2- } \\
\text { WV7.3 }\end{array}$ & $-25 \mathrm{~K}$ & $0 \mathrm{~K}$ & Linear & IR9.7-IR10.8 & $-40 \mathrm{~K}$ & $5 \mathrm{~K}$ & Linear & WV6.2 inverted & $208 \mathrm{~K}$ & $243 \mathrm{~K}$ & Linear \\
\hline
\end{tabular}

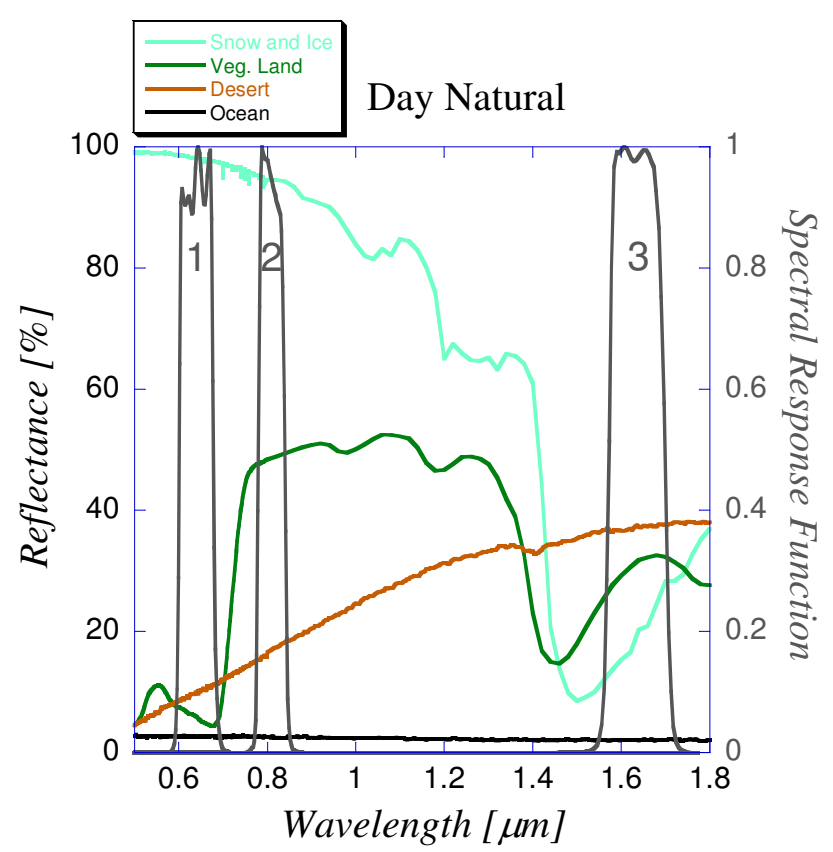

Fig. 4. Spectral response functions of the three channels of the "Day Natural Color" scheme and spectral signatures of few materials.

(1998): the $0.8 \mu \mathrm{m}$ reflectance in red approximates the cloud optical depth and amount of cloud water and ice; the $3.9 \mu \mathrm{m}$ solar reflectance in green is a qualitative measure for cloud particle size and phase, and the $10.8 \mu \mathrm{m}$ brightness temperature modulates the blue. This color scheme is useful for cloud analysis, convection, fog, snow, and fires. In this color scheme water clouds that do not precipitate appear white $(\mathrm{C}$,

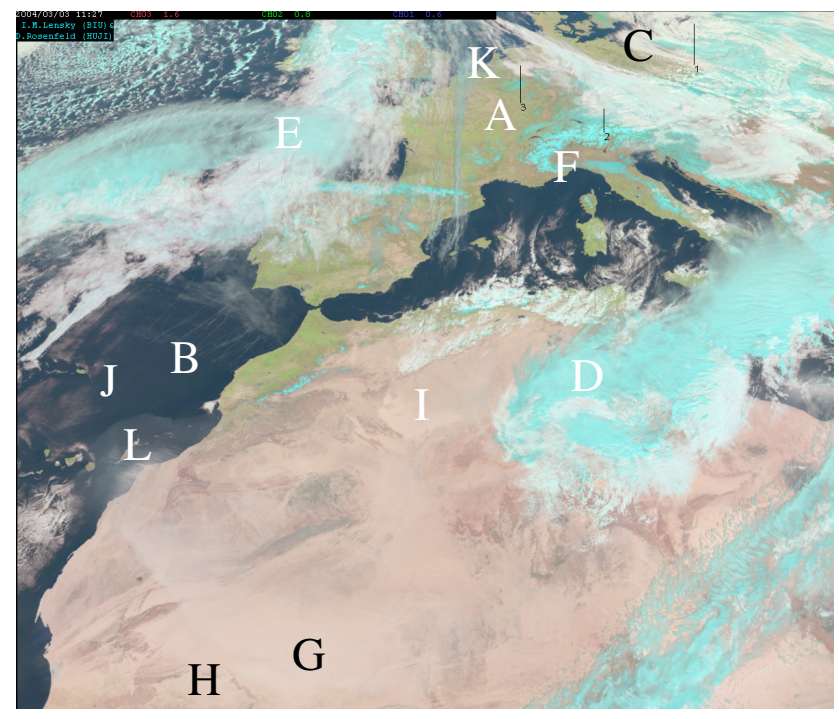

Fig. 5. The "Day Natural Colors Enhanced" is the same as Fig. 3, only $\Gamma=3$ is used to stretch all the three beams. This color scheme is useful for detecting dust (L), very thin clouds and contrails (B) over the sea.

M) because cloud drops are small, whereas large drops that are typical to precipitating clouds appear pink $(\mathrm{N})$, because of the low reflectance at $3.9 \mu \mathrm{m}$ manifested as low green. Supercooled water clouds $(\mathrm{O})$ appear more yellow, because the lower temperature that modulate the blue component. Cold and thick clouds with tops composed of large ice particles, e.g. Cb tops, appear red (D). Optically thick clouds with small ice particles near their tops (E) appear orange. Thin clouds composed of small ice particles such as contrails 


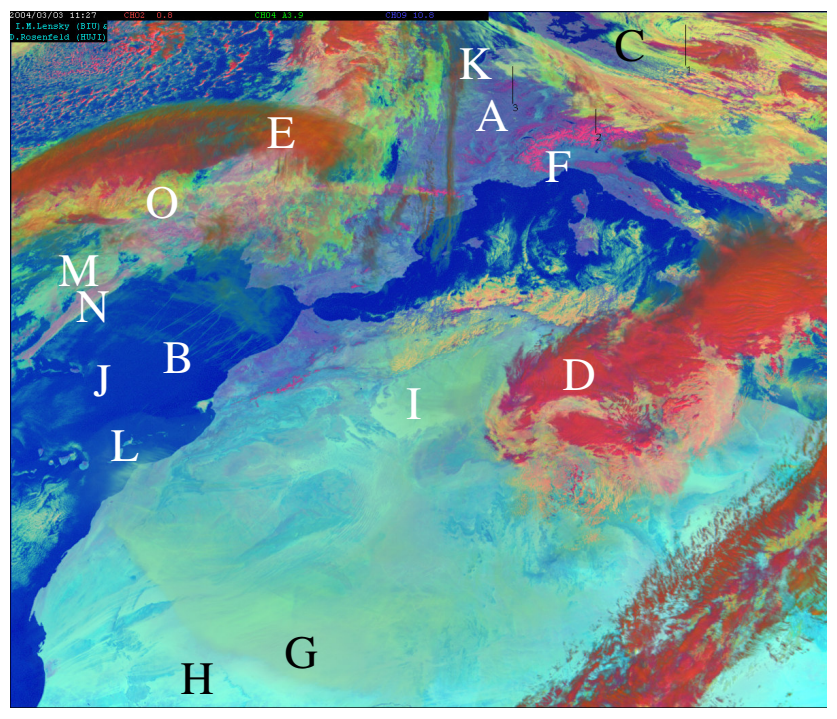

Fig. 6. With the RGB composition for the "Day Microphysical" color scheme, water clouds (C), contrails (B), ice clouds (D), ice clouds with small particles (E), snow (F), and fires can be detected.

appear as faint green (B), and thin clouds composed of large ice crystals appear dark (K). Typical values and the resulting colors are given in Table 2.

\subsection{Day solar}

Figure 7 shows an RGB composition for the "Day Solar" color scheme: $0.8,1.6$ and $3.9 \mu \mathrm{m}$ solar reflectance in the red green and blue beams respectively. Figure 8 shows the spectral response functions of the three channels of the "Day Solar" color scheme and spectral signatures of several objects. In this color scheme vegetation (A) appears greenish because of the large reflectance in the 1.6 and $0.8 \mu \mathrm{m}$ channels (the red and green beams). Snow (F) appears red because of the strong absorption in 1.6 and $3.9 \mu \mathrm{m}$ (no green and blue), small particle ice cloud (E) appears orange, while large particle ice cloud (D) appears with greater red component. Snow on the ground (F) appears as full red, because its grains are usually much larger than cloud ice particles. Water clouds with small droplets $(\mathrm{C}, \mathrm{M})$ have large reflectance in the $3.9 \mu \mathrm{m}$ channel appears bright yellow. The dynamic range of reflected sun light from different ice particles is larger at $1.6 \mu \mathrm{m}$ than in $3.9 \mu \mathrm{m}$, enabling us to discriminate ice particle size. Typically ice particles that form by mixed phase process in a super cooled water cloud grow quickly to much larger sizes than crystals forming by vapor deposition in ice-only clouds. This helps separating convective precipitating clouds from non-precipitating or layer ice clouds. However, small ice particles can occur also at the tops of severe convective storms or high base convective clouds, because cloud drops freeze directly into ice crystals by the mechanism of homogeneous nucleation (Rosen-

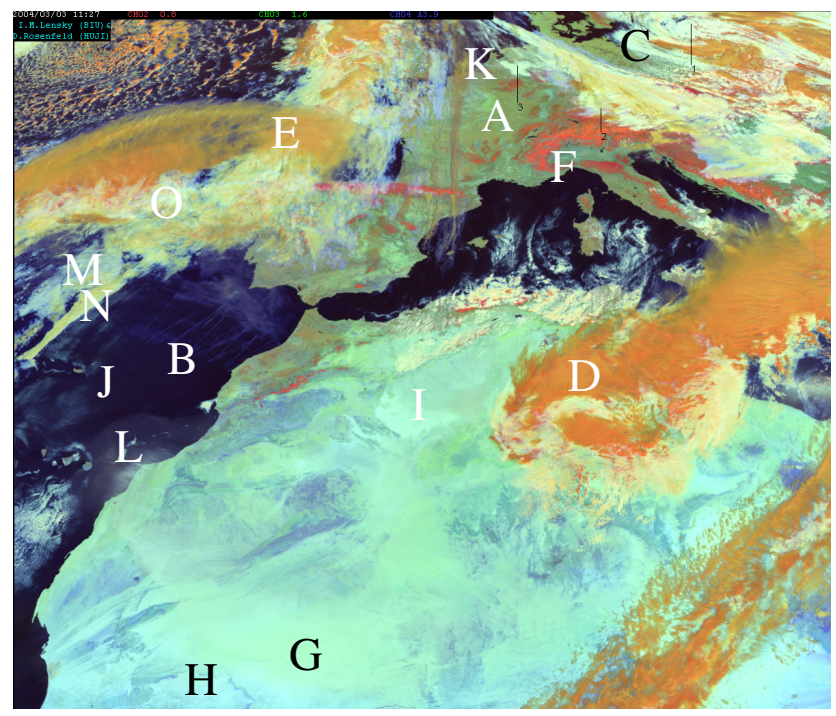

Fig. 7. With the RGB composition for the "Day Solar" color scheme, vegetation (A), water clouds (C), ice clouds (D), ice clouds with small particles (E), snow (F), and fires can be detected.

feld et al., 2006). Deserts (H) appear bright cyan because of the larger reflectance in the 1.6 and especially at $3.9 \mu \mathrm{m}$. Sea surface (J) appears black because of the low reflectance in all three bands. This color scheme is very sensitive to cloud microphysics, but there is no information from the thermal channels about the temperature (vertical extent) of the clouds. The main applications of this color scheme are: cloud analysis, convection, fog, snow, and fires. Typical values and the resulting colors are given in Table 2.

\subsection{Convective storms}

In the "Convective Storms" color scheme (Fig. 9) the brightness temperature difference (BTD) between 6.2 and $7.3 \mu \mathrm{m}$ channels $\left(\mathrm{BTD}_{6.2-7.3}\right)$ is regulating the red, which is modulated by the mid level moisture. Overshooting $\mathrm{Cb}$ clouds have near zero or even slightly positive $\mathrm{BTD}_{6.2-7.3}$ (red). $\mathrm{Cb}$ tops (D) that do not extend to the tropopause show small negative values while the surface (A) shows large negative BTD $_{6.2-7.3}$ values (no red). The BTD between 3.9 and $10.8 \mu \mathrm{m}$ channels $\left(\mathrm{BTD}_{3.9-10.8}\right)$ modulates the green and indicates the microphysics. At daytime, the large solar reflectance from small cloud particles at $3.9 \mu \mathrm{m}$ is added to the thermal contribution at this wavelength, contributing to a larger $\mathrm{BTD}_{3.9-10.8}$. This effect is stronger for cold clouds because the fraction of the added solar radiation is larger when the thermal radiation is relatively small. The difference between the 1.6 and 0.6 solar reflectances $\left(\mathrm{RD}_{1.6-0.6}\right)$ modulates the blue, where large negative $\mathrm{RD}_{1.6-0.6}$ indicates ice clouds and much larger $\mathrm{RD}_{1.6-0.6}$ is typical for the surface (see Fig. 4). Severe convective storms (E) appear bright yellow in this color scheme because of the near zero $\mathrm{BTD}_{6.2-7.3}$ 
Table 2. Typical physical values (reflectance/temperatures) and the RGB color for different objects in the color schemes using solar reflectance ( $T$ and BTD in degrees Celsius, $A$ in \%).

\begin{tabular}{lccc}
\hline Day Natural Colors & $A_{1.6}$ & $A_{0.8}$ & $A_{0.6}$ \\
\hline Vegetation & 25 & 45 & 8 \\
Water clouds - small droplets & 60 & 75 & 70 \\
Snow and ice clouds & 25 & 75 & 70 \\
Bare ground & 60 & 40 & 30 \\
Ocean & 1 & 3 & 4 \\
\hline Day Natural Colors Enhanced & $A_{1.6}$ & $A_{0.8}$ & $A_{0.6}$ \\
\hline Vegetation & 25 & 45 & 8 \\
Water clouds - small droplets & 60 & 75 & 70 \\
Snow and ice clouds & 25 & 75 & 70 \\
Bare ground & 60 & 40 & 30 \\
Ocean & 1 & 3 & 4 \\
\hline Day Microphysical & $A_{0.8}$ & $A_{3.9}$ & $T_{10.8}$ \\
\hline Cb clouds & 99 & 2.5 & -60 \\
Cb clouds - small droplets & 88 & 13 & -60 \\
Water clouds with small particles & 65 & 30 & -8 \\
Maritime stratocumulus & 55 & 10 & 12 \\
Ship trails & 55 & 20 & 12 \\
\hline Day Solar & $A_{0.8}$ & $A_{1.6}$ & $A_{3.9}$ \\
\hline Vegetation & 45 & 25 & 5 \\
Snow & 72 & 11 & 3 \\
Small particle ice cloud & 100 & 50 & 7 \\
Large particle ice cloud & 80 & 30 & 2 \\
Water clouds with small particles & 65 & 60 & 30 \\
Maritime stratocumulus & 55 & 46 & 10 \\
Ship trails & 55 & 50 & 20 \\
Desert & 41 & 55 & 100 \\
Ocean & 2 & 0.5 & 0 \\
\hline Convective Storms & $B T D_{6.2-7.3}$ & $B T D_{3.9-10.8}$ & $A_{1.6-0.6}$ \\
\hline Severe convective storms & -2 & 60 & -20 \\
Cb clouds & -8 & 20 & -40 \\
\hline
\end{tabular}

of overshooting $\mathrm{Cb}$ clouds (high red). The strong updrafts in these clouds produce small ice particles at cloud tops due to homogeneous freezing of cloud drops (Rosenfeld et al., 2006), resulting with large $\mathrm{BTD}_{3.9-10.8}$ (high green). Finally, large negative $\mathrm{RD}_{1.6-0.6}$ because of the large absorption at $1.6 \mu \mathrm{m}$ by ice particles keeps the blue very low. Small ice crystals of Cirrus clouds (E in Fig. 9b) should not be confused with vigorous convection (as in Fig. 9a). Typical values and the resulting colors are given in Table 2. Inferred small ice crystals that are not associated with anvils of $\mathrm{Cb}$ clouds must form by elevated strong updrafts, such as in high altitude orographic wave clouds. For example see the small cloud over the eastern edge of the Alps to the right of $(\mathrm{F})$. "Day microphysical" RGB can separate Cb from thin cirrus clouds that are both composed of small ice crystals.

\section{Color schemes that do not use solar reflectance}

The "Day Microphysical" color scheme relies on solar radiation and is hence useful during daylight hours only. Two schemes that do not rely on solar radiation, but still provide similar colors as those of the daytime scheme for the same cloud properties are presented here. Both the "Night Microphysical" (Fig. 10) and "Day and Night" (Fig. 11) color schemes use only channels in the thermal IR. The BTD between the 12.0 and $10.8 \mu \mathrm{m}$ channels $\left(\mathrm{BTD}_{12.0-10.8}\right)$ is a measure for the clouds' opaqueness (Inoue, 1987), therefore it is displayed in red as the $0.8 \mu \mathrm{m}$ reflectance at daytime in the "Day Microphysical" color scheme. The $10.8 \mu \mathrm{m}$ brightness temperature modulates the blue as is in the "Day Microphysical" color scheme, only that the minimum and maximum values differ. Figure 2 shows that channel $4(3.9 \mu \mathrm{m})$ is most sensitive to clouds' particle effective radius, followed by channel $7(8.7 \mu \mathrm{m})$. Therefore the "Night Microphysical" color scheme uses channel $4(3.9 \mu \mathrm{m})$, while the "Day and Night" color scheme uses channel $7(8.7 \mu \mathrm{m})$. This is demonstrated in Fig. 14, where ship tracks can be seen clearly using the "Night Microphysical" color scheme, very faintly with the "Day and Night", and not at all with the "Dust" color schemes. 


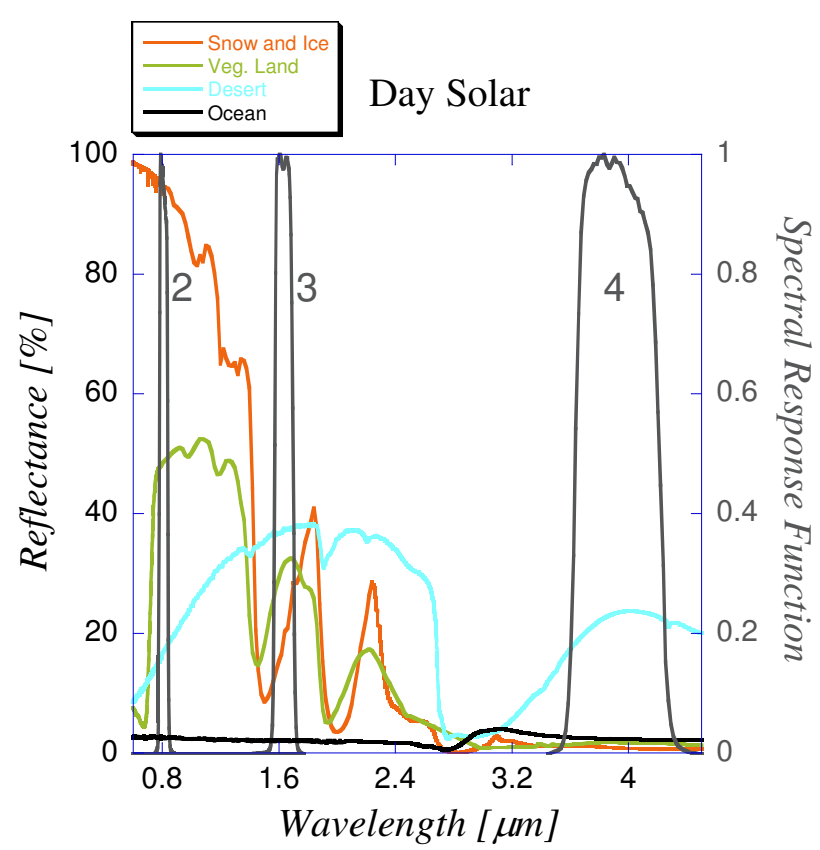

Fig. 8. The spectral response functions of the three channels of the "Day Solar" color scheme and spectral signatures of several objects.

\subsection{Night microphysical}

The BTD between 10.8 and $3.9 \mu \mathrm{m}$ channels $\left(\mathrm{BTD}_{10.8-3.9}\right)$ modulates the green beam in the "Night Microphysical" color scheme (Fig. 10). Lensky and Rosenfeld (2003a) showed how sensitive is the $\mathrm{BTD}_{10.8-3.9}$ to particle size, and used this information to delineate precipitation (Lensky and Rosenfeld, 2003b). Figure 2 shows that the $3.9 \mu \mathrm{m}$ emissivity is much smaller for clouds composed of small drops (0.85) than for large drops (0.99) while at $10.8 \mu \mathrm{m}$ both show large values $(0.98-0.99)$, therefore large $\mathrm{BTD}_{10.8-3.9}$ will indicate clouds with small drops. Nighttime shallow clouds or fog with small drops appears in this color scheme in white (A). If the water clouds or fog are colder (B, C) they appear more in yellow colors. Water clouds with larger drops have greater red component, as shown in Fig. 10. The radiation emitted from the tops of cold $\mathrm{Cb}(<220 \mathrm{~K})$ in $3.9 \mu \mathrm{m}$ is very low, resulting with low signal to noise ratio and sprinkled color at the Cb tops. Therefore deep Cb clouds (D) at night appear in sprinkled orange-red color. Typical values and the resulting colors are given in Table 3.

\section{2 "Day and Night" and "Desert Dust"}

The "Day and Night" (Fig. 11a) and the "Desert Dust" (Fig. 11b) are the same color schemes, just with RGB dynamic range adjusted for maximum sensitive for clouds in the "Day and Night" color scheme, and for dust in the "Desert Dust" color scheme (see Table 1). The BTD between 10.8 and $8.7 \mu \mathrm{m}$ channels $\left(\mathrm{BTD}_{10.8-8.7}\right)$ modulates the green

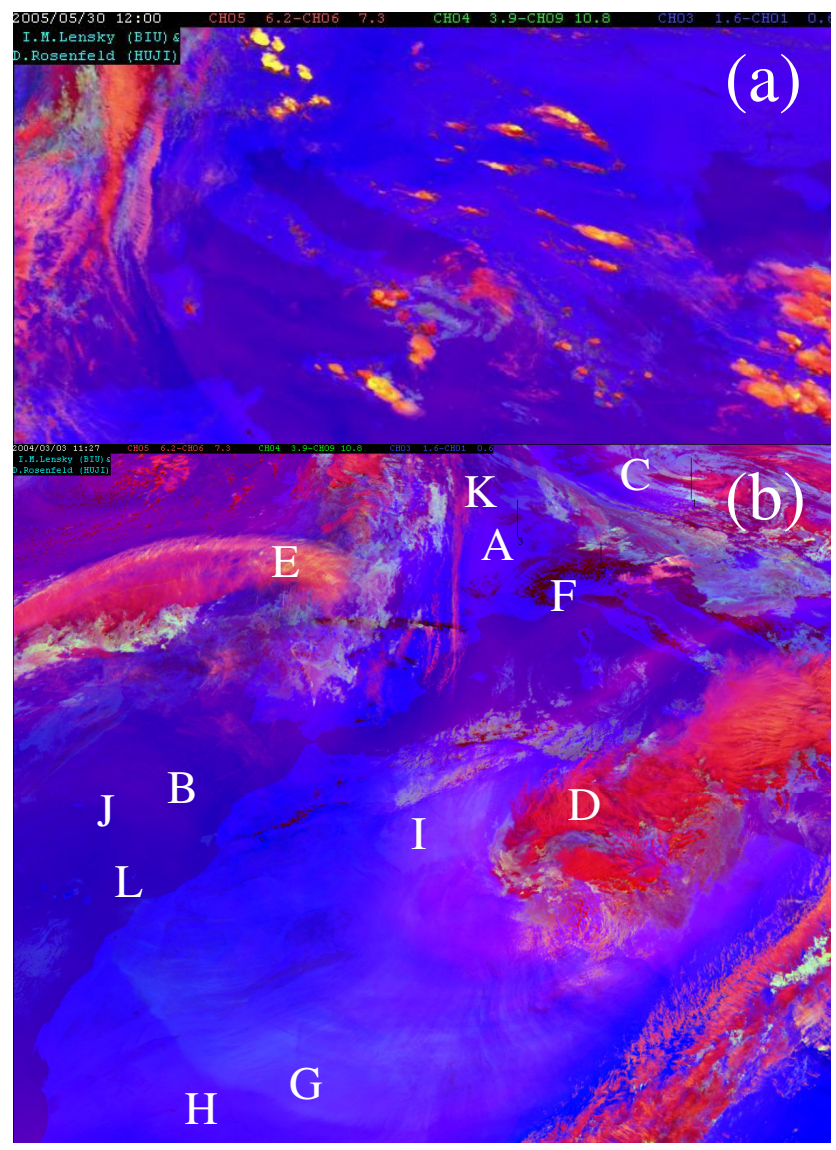

Fig. 9. "Convective Storms" color scheme. (a) Vigorous and severe convective storms appear bright yellow in this color scheme because of the small negative $\mathrm{BTD}_{6.2-7.3}$ of $C_{b}$ clouds (high red). The strong updrafts in these clouds produce small ice particles at cloud tops resulting with large $\mathrm{BTD}_{3.9-10.8}$ (high green). The large absorption at $1.6 \mu \mathrm{m}$ by these ice particles keeps the blue very low. Small ice crystals of Cirrus clouds (E in panel b) should not be confused for vigorous convection (a).

beam in these color schemes. The emissivity of large particles of quartz mineral $(125-500 \mu \mathrm{m})$ is very low in $8.7 \mu \mathrm{m}$ (see Fig. 12), thus the $\mathrm{BTD}_{10.8-8.7}$ is very large over sands with quartz mineral in the desert $(\mathrm{H})$, together with relative high BTD $_{12.0-10.8}$ and warm temperatures, the color of the desert sand is whitish. The emissivity in $8.7 \mu \mathrm{m}$ of small quartz mineral particles $(0-45 \mu \mathrm{m})$ in the desert dust $(\mathrm{G})$ is much larger, resulting in smaller $\mathrm{BTD}_{10.8-8.7}$ and very strong pink colors. This color scheme is also useful for day and night detection of contrails (B). As in the "Day Microphysical", deep Cb clouds (E) appear red: positive $\mathrm{BTD}_{12.0-10.8}$ revealing opaque clouds and high red, large ice particles resulting with small $\mathrm{BTD}_{10.8-8.7}$ and low green, and cold tops - low blue. Thick water clouds (C) appear yellow: larger

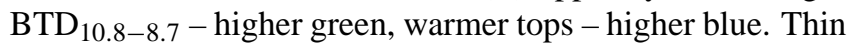
Ci clouds appear black, while clouds with small particles appear green. The colors of thin clouds may be affected by the 
Table 3. Same as Table 2 only for color schemes that do not use solar reflectance ( $T$ and BTD in degrees Celsius).

\begin{tabular}{lccc}
\hline Night Microphysical & BTD $_{12.0-10.8}$ & BTD $_{10.8-3.9}$ & $T_{10.8}$ \\
\hline Deep Cb clouds & 0 & -10 & -50 \\
Clouds with small particles & 0 & 5 & 0 \\
Sea & -2 & -2 & 20 \\
Warm ground & 1 & 2 & 20 \\
Cold ground & 0 & 3 & 7 \\
\hline Desert Dust & BTD $_{12.0-10.8}$ & BTD $_{10.8-8.7}$ & $T_{10.8}$ \\
\hline Deep Cb clouds & -0.5 & -1 & -60 \\
Thick water clouds & -0.5 & 1 & -10 \\
Clouds with small particles & -6 & 3 & 0 \\
Thin Ci clouds & -4 & -4 & -40 \\
Desert dust & 3 & -2 & 10 \\
Sands with quartz mineral & 1 & 12 & 35 \\
\hline Day and Night & $\mathrm{BTD}_{12.0-10.8}$ & $\mathrm{BTD}_{10.8-8.7}$ & $T_{10.8}$ \\
\hline Deep Cb clouds & -0.5 & -1 & -60 \\
Thick water clouds & -0.5 & 1 & -10 \\
Clouds with small particles & -6 & 3 & 0 \\
Thin Ci clouds & -4 & -4 & -40 \\
Desert dust & 3 & -2 & 10 \\
Sands with quartz mineral & 1 & 12 & 35 \\
\hline Air Mass & $\mathrm{BTD}_{6.2-7.3}$ & $\mathrm{BTD}_{9.7-10.8}$ & $T_{6.2}$ \\
\hline Thick, high-level clouds & -1 & 10 & -60 \\
Thick, mid-level clouds & -5 & -5 & -50 \\
Rich Ozone Polar air mass & -20 & -35 & -40 \\
Dry descending stratospheric air & -16 & -33 & -30 \\
Low Ozone tropical air mass & -22 & -22 & -32 \\
\hline
\end{tabular}

underlying surface properties (temperature and emissivity). Typical values and the resulting colors are given in Table 3.

\subsection{Air mass}

The RGB composition for the "Air Mass" color scheme (Fig. 15) is: BTD $_{6.2-7.3}$ modulates the red as in the "Convective Storms" color scheme, where dry atmosphere has values close to zero (reddish), and moist atmosphere has negative values. The BTD between 9.7 (ozone) and $10.8 \mu \mathrm{m}$ channels (BTD $9.7-10.8)$ modulates the green, where rich ozone polar air mass has large negative BTD $9.7-10.8$ (bluish), while low ozone tropical air mass has small negative BTD $9.7-10.8$ (greenish). The $6.2 \mu \mathrm{m}$ water vapor channel modulates inversely the blue beam, where moist atmosphere shows bluish colors. Dry descending stratospheric air related to an advection jet appears in reddish colours. This color scheme is useful for studying Rapid Cyclogenesis, Jet Stream Analysis, and PV Analysis. Typical values and the resulting colors are given in Table 3.

\section{Using combination of RGB compositions}

Cloud drop size is a major factor in cloud microstructure that determines their precipitation forming processes. Ship tracks represent the best natural laboratory for the ability to discern clouds with small drops that do not precipitate from drizzling clouds with large drops. Figures 13 and 14 provide the way cloud microstruture in the context of ship tracks in marine stratocumulus can be seen differently in the various solar (day) and thermal (night) RGB compositions, respectively. It is shown that the "Day Microphysical" RGB is the most sensitive to cloud drop size, followed by "Night Microphysical". Other schemes are less sensitive to cloud drop size or not at all.

Ship tracks serve the purpose to demonstrate the sensitivity of the various RGB schemes to cloud microstructure in the simplest clouds of all - maritime stratocumulus. $\mathrm{Mi}$ crostructure variability of other kinds of cloud is much more complex and less readily understandable, but it still dominates the RGB colors and provides the best means for viewing cloud composition on large scales. Figure 16 displays four RGB color paletts for such complex clouds with: (a) "Day Microphysical" (from Fig. 6); (b) "Day Natural" (from Fig. 3); (c) "Desert Dust" (from Fig. 11b); and (d) "Day Solar" (from Fig. 7) color schemes. Three cross sections can be seen in these RGB figures: 1. over highly supercooled water and ice clouds; 2 . over snow, ice and water clouds; and 3. over bare surface, snow and fog or stratus. The plots of the physical parameters (reflectance and brightness temperature) of these cross sections are displayed in Fig. 17. 


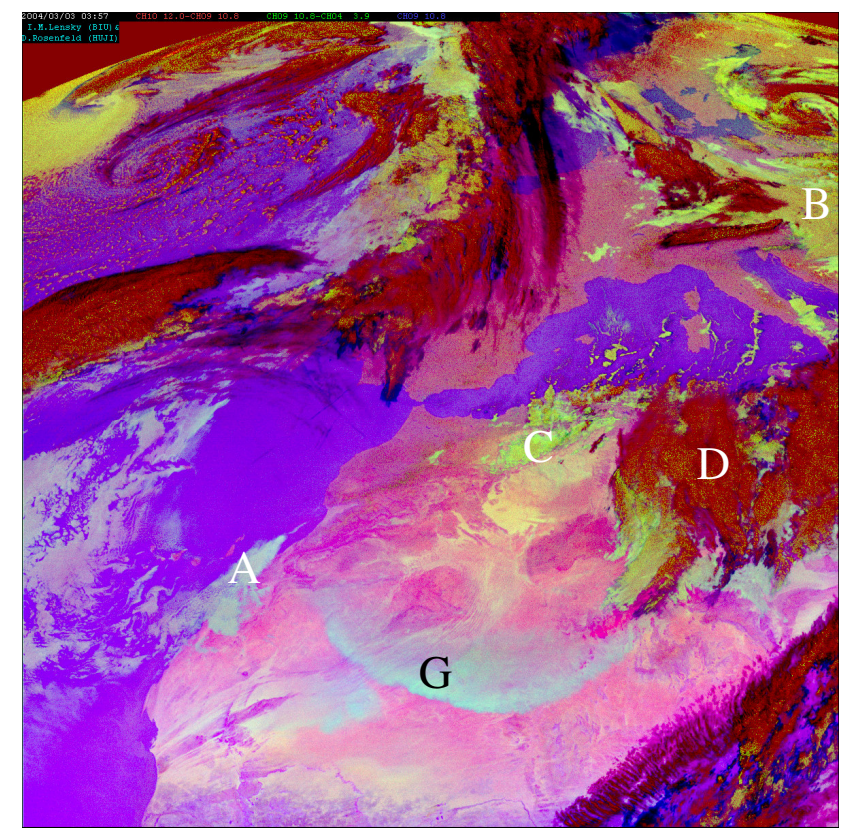

Fig. 10. In the "Night Microphysical" color scheme, water clouds with small drops appear white (A), and yellow when become supercooled (B, C). Cb clouds with cold tops and ice particles appear in red (D). Dust (G) is also identified in this color scheme.

In the southern part (lines 3406-3420) and the northern part (lines 3445-3465) of the first cross section (Fig. 17a), super cooled water clouds are identified by the high solar reflectance of about $70 \%$ in the $1.6 \mu \mathrm{m}$ channel (green line) and $30-40 \%$ in the $3.9 \mu \mathrm{m}$ channel (red line). Also, the large BTD $_{10.8-8.7}$ (the difference between the purple dashed line of the $10.8 \mu \mathrm{m}$ channel and the solid blue line of the $8.7 \mu \mathrm{m}$ channel) of about $4^{\circ} \mathrm{C}$ is indicative of small particles in these super cooled water clouds. Between lines 3422 and 3432 the low reflectances ( $\sim 5 \%$ in $3.9 \mu \mathrm{m}$ channel and $\sim 25 \%$ in the $1.6 \mu \mathrm{m}$ channel) are indicating strong absorption by ice particles. The coldest pixel $\left(-37^{\circ} \mathrm{C}\right)$ is in line 3436 , showing high reflectance in the 1.6 and the $3.9 \mu \mathrm{m}$ channels and $\mathrm{BTD}_{10.8-8.7}$ of $\sim 2^{\circ} \mathrm{C}$, indicating the presence of highly supercooled thin water cloud. In Fig. 16 the super cooled water and ice clouds can be easily identified in all four color schemes by the different colors: (a) water - yellow, ice - red; (b) water - white, ice - magenta; (c) water - orange, ice red; (d) water - white, ice - orange.

Cross section number 2 in Fig. 16 is over snow (south), ice (center), high water cloud (center north) and water (north) clouds. In Fig. 17b, in the southern part (lines 3307-3325) the $0.8 \mu \mathrm{m}$ solar reflectance (black line) oscillates between $\sim 90 \%$ over the colder snowy tops of the Alpes $\left(-10^{\circ} \mathrm{C}\right)$ and the warmer $\left(0-5^{\circ} \mathrm{C}\right)$ and less snowy valleys $(\sim 60 \%)$. Between lines 3327 and 3334 the low reflectances $(\sim 5 \%$ in $3.9 \mu \mathrm{m}$ channel and $\sim 20 \%$ in the $1.6 \mu \mathrm{m}$ channel) are indicating strong absorption by ice particles in cloud tops of

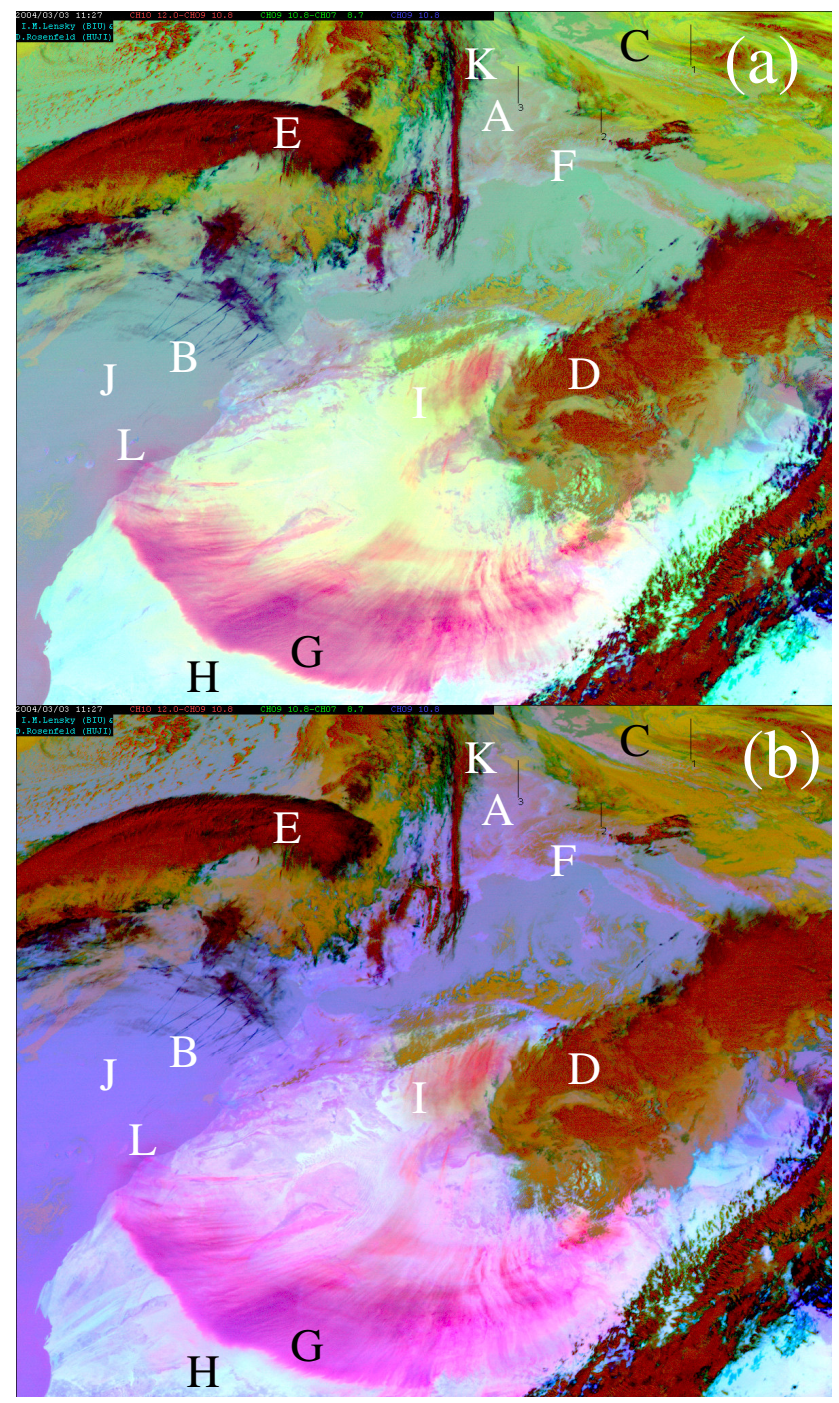

Fig. 11. (a) In the "Day and Night" color scheme desert sand is whitish $(\mathrm{H})$, but desert dust has very strong pink colors $(\mathrm{G})$. This color scheme is also useful for day and night detection of contrails (B). (b) The "Desert Dust" color scheme is the same as the "Day and Night" RGB color scheme (panel a) only that in the "Day and Night" color scheme the extreme values of the green and blue beams are adjusted for maximum sensitivity for cloud microphysics and in the "Desert Dust" color scheme the extreme values of the green and blue beams are adjusted for maximum sensitivity for dust (see Table 1).

$-27^{\circ} \mathrm{C}$. From line 3335 to line 3337 , the higher reflectance in the 1.6 and $3.9 \mu \mathrm{m}$ channels and the larger $\mathrm{BTD}_{10.8-8.7}$ (the difference between the purple dashed line of the $10.8 \mu \mathrm{m}$ channel and the solid blue line of the $8.7 \mu \mathrm{m}$ channel) are indicating that small supercooled water drops are present at cloud tops (with the same temperature of $-27^{\circ} \mathrm{C}$ ). Further to the North, lower water clouds with warmer temperatures $\left(-10^{\circ} \mathrm{C}\right)$ and higher solar reflectance in the three solar channels displayed here can be seen. In Fig. 16 the snow, 


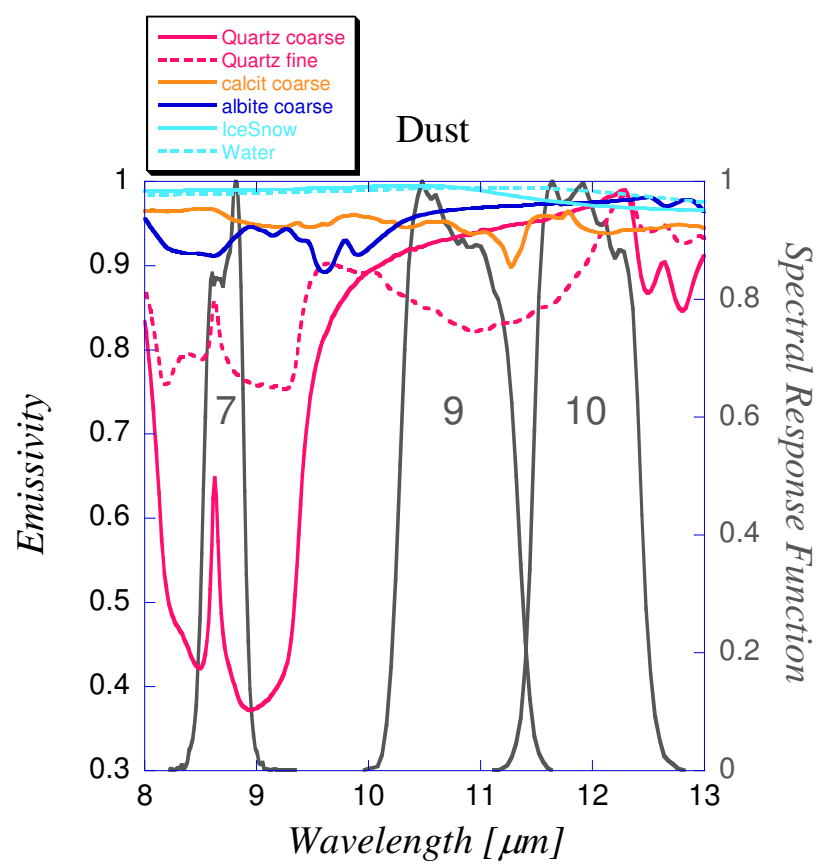

Fig. 12. The emissivity of large particles of quartz mineral (125$500 \mu \mathrm{m})$ is very low in $8.7 \mu \mathrm{m}$, thus BTD $10.8-8.7$ is very large over sands with quartz mineral. The emissivity in $8.7 \mu \mathrm{m}$ of small quartz mineral particles $(0-45 \mu \mathrm{m})$ in the desert dust is much larger, resulting with smaller $\mathrm{BTD}_{10.8-8.7}$.

ice and water clouds can be identified by the different colors: (a) snow - pink, ice clouds - red, water clouds - yellow; (b) snow - bright magenta, ice clouds - magenta, water clouds - white; (c) snow - orange, ice clouds - red, water clouds - green; (d) snow - red, ice clouds - orange, water clouds - white.

Cross section number 3 in Fig. 16 is over surface (south), snow (center) and fog or stratus (north). In Fig. 17c, in the southern part (lines 3350-3370) the warm temperatures $\left(5-10^{\circ} \mathrm{C}\right)$ and solar reflectance are typical of bare soil and vegetated surface. Snow on the surface between lines 3370 and 3385 highly reflects the solar radiation at $0.8 \mu \mathrm{m}(50$ $60 \%)$ and absorbs the solar radiation at $1.6 \mu \mathrm{m}(10-15 \%)$ and $3.9 \mu \mathrm{m}(0-5 \%)$. The fog or stratus just north of the snow (lines 3390-3404) highly reflects the radiation at all the solar channels, indicating small droplets. In Fig. 16 the surface, snow, and fog can be identified by the different colors: (a) surface - blue, snow - pink, fog - yellow; (b) surface green, snow - magenta, fog - white; (c) surface - purple, snow - red, fog - yellow; (d) surface - green, snow - red, fog - white.

\section{Summary}

The availability of large number of spectral channels from meteorological satellites in general, and the METEOSAT

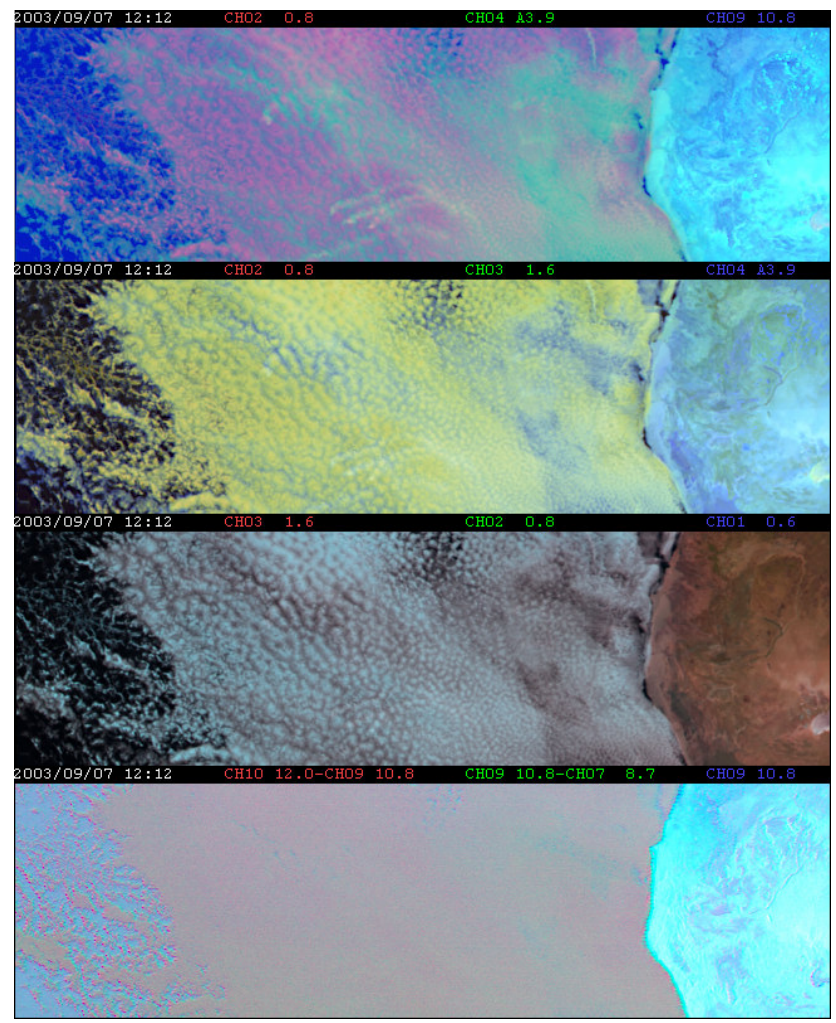

Fig. 13. The $3.9 \mu \mathrm{m}$ channel in the "day microphysical" color scheme (upper panel) is the most sensitive channel to cloud microphysics. This is demonstrated by ship tracks, which are also seen in the "day solar" color scheme (second from top) but not in the "day natural colors" (third from top) or the "Day and Night" color schemes (lower panel).

Second Generation in particular, provide us with new ways to look at clouds, aerosols and Earth surface. The most basic and immediate way to gain insights is to use RGB combinations. Here we introduce several useful RGB conventions that have been already become commonly used by the MSG user community.

The different RGB combinations have relative advantage for observing different phenomena. "Day microphysical" is the preferable scheme for observing the microstructure of water and mixed phase clouds during daylight hours; "Night microphysical" is the most appropriate scheme for inferring cloud microstructure during night time; "Desert dust" is best for detecting cloud phase consistently during both day and night, as well as observing desert dust clouds; "Day natural colors" approximates best the colors that are closest to true colors of land surface, including green vegetation and brown exposed soil. It also discerns well between water and ice clouds. "Day solar" is somewhat more sensitive to cloud microstructure than "Day microphysical", but it lacks the information about cloud top temperatures and has reduced delectability of thin clouds; "Convective storms" highlight very cold clouds composed of small ice crystals. Such clouds 


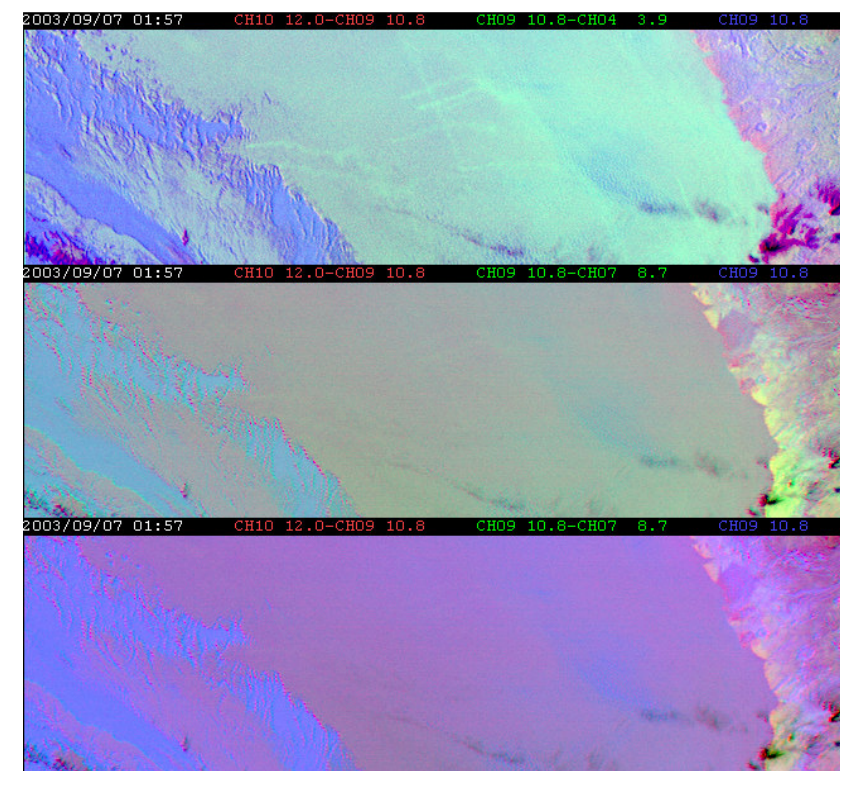

Fig. 14. The $3.9 \mu \mathrm{m}$ channel in the "Night Microphysical" color scheme (upper panel) is the most sensitive channel to cloud microphysics. This is demonstrated by ship tracks, which are not seen in the "Day and Night" color scheme (middle panel) or the "Dust" color scheme (lower panel).

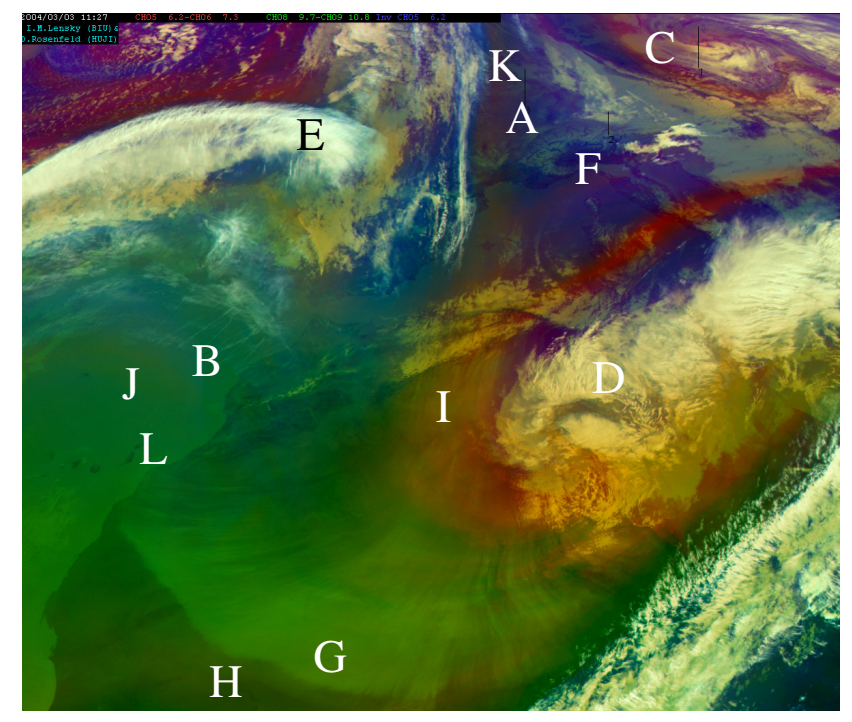

Fig. 15. In the "Air Mass" color scheme, rich ozone polar air mass will have large negative BTD $_{9.7-10.8}$ (bluish), while low ozone tropical air mass will have small negative BTD $9.7-10.8$ (greenish).

can be the tops of vigorous $\mathrm{Cb}$, or strongly rising air motion originating at high levels, such as orographic wave clouds.

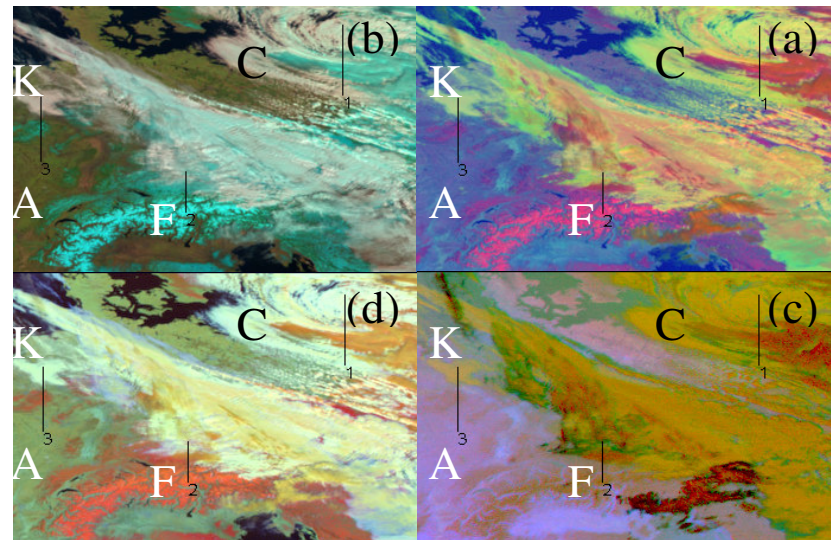

Fig. 16. Three cross sections over: 1 . water and ice clouds; 2 . snow, ice and water clouds; and 3. surface, snow and fog. The three cross sections are displayed on: (a) "Day Microphysical" (Fig. 5); (b) "Day Natural" (Fig. 3); (c) "Desert Dust" (Fig. 11b); and (d) "Day Solar" (Fig. 7) color schemes. The plots of the cross sections are displayed in Fig. 17.

\section{Appendix A}

\section{Data preparation}

A1 Conversion of channel data to brightness temperatures and reflectance

The relation between the 10 bit pixel Count and the physical spectral radiance $(B)$ in $\mathrm{mW} \mathrm{m}^{-2} \mathrm{sr}^{-1}\left(\mathrm{~cm}^{-1}\right)^{-1}$ is defined for each spectral band by Eq. (A1):

$B=$ offset + slope $\cdot$ Count,

where "offset" is an offset constant between the pixel count and the physical radiance, and "slope" is a linear calibration coefficient, both extracted either from the on-board calibration (for IR channels) or from other sources (e.g. SEVIRI Solar Channel Calibration (SSCC) for solar channels). The units are $\mathrm{mW} \mathrm{m}^{-2} \mathrm{sr}^{-1}\left(\mathrm{~cm}^{-1}\right)^{-1}$.

The relation between the radiance $(B)$ and $T$ for the MSG thermal IR channels is given by the Planck function in Eq. (A2):

$$
B(T)=\frac{C_{1} v_{c}^{3}}{\left(e^{C_{2} v_{c} /(a T+b)}-1\right)} .
$$

Where: $\quad C_{1}=1.19104 \times 10^{-5} \mathrm{~mW} \mathrm{~m}^{-2} \mathrm{sr}^{-1} \quad\left(\mathrm{~cm}^{-1}\right)^{-4}$, $C_{2}=1.43877 \mathrm{~K}\left(\mathrm{~cm}^{-1}\right)^{-1}, v_{c}$ is the central wave number of the channel in $\mathrm{cm}^{-1}$, and $a$ and $b$ are coefficients (see Table A1). 

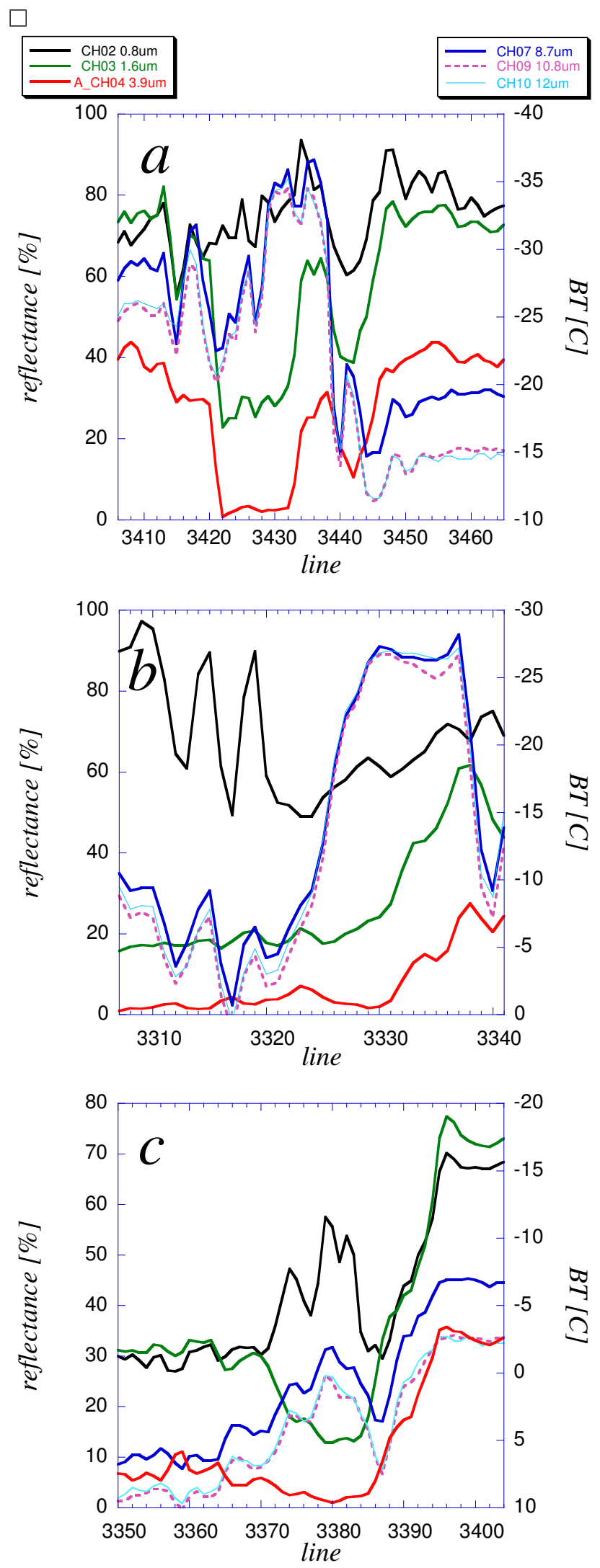

Fig. A1. (a) Cross section number 1 in Fig. 16, over water and ice clouds. In the southern part (lines 3406-3420) and the northern part (lines 3445-3465) of the cross section super cooled water clouds are identified by the high solar reflectance of about $70 \%$ in the $1.6 \mu \mathrm{m}$ channel (green line) and 30-40\% in the $3.9 \mu \mathrm{m}$ channel (red line). Also, the large BTD $_{10.8-8.7}$ (the difference between the purple dashed line of the $10.8 \mu \mathrm{m}$ channel and the solid blue line of the $8.7 \mu \mathrm{m}$ channel) of about $4^{\circ} \mathrm{C}$ is indicative of small particles in these super cooled water clouds. Between lines 3422 and 3432 the low reflectance $(\sim 5 \%$ in $3.9 \mu \mathrm{m}$ channel and $\sim 25 \%$ in the $1.6 \mu \mathrm{m}$ channel) are indicating strong absorption by ice particles. The coldest pixel $\left(-37^{\circ} \mathrm{C}\right)$ is in line 3436 , showing high reflectance in channels 3 and 4 and $\mathrm{BTD}_{10.8-8.7}$ of $\sim 2^{\circ} \mathrm{C}$, indicating the presence of small highly supercooled cloud drops just at the threshold of homogeneous glaciation temperature. (b) Cross section number 2 in Fig. 16 over snow, ice and water clouds. In the southern part (lines 3307-3325) the $0.8 \mu \mathrm{m}$ solar reflectance (black line) oscillates between $\sim 90 \%$ over the colder snowy tops of the Alpine mountain $\left(-10^{\circ} \mathrm{C}\right)$ tops and the warmer $\left(0--5^{\circ} \mathrm{C}\right)$ and less snowy valleys $(\sim 60 \%)$. Between lines 3327 and 3334 the low reflectance $(\sim 5 \%$ in $3.9 \mu \mathrm{m}$ channel and $\sim 20 \%$ in the $1.6 \mu \mathrm{m}$ channel) are indicating strong absorption by ice clouds. From line 3335 to line 3337 , the higher reflectance in channels 3 and 4 and the larger $\mathrm{BTD}_{10.8-8.7}$ (the difference between the purple dashed line of the $10.8 \mu \mathrm{m}$ channel and the solid blue line of the $8.7 \mu \mathrm{m}$ channel) are indicating that small supercooled drops are present at cloud tops. Further to the North, lower water clouds with warmer temperatures $\left(-10^{\circ} \mathrm{C}\right)$ and higher solar reflectance in the three solar channels displayed here can be seen. (c) Cross section number 3 in Fig. 16 over surface, snow and fog. In the southern part (lines 3350-3370) the warm temperatures $\left(5-10^{\circ} \mathrm{C}\right)$ and solar reflectance are typical of bare soil and vegetated surface. Snow on the surface between lines 3370 and 3385 highly reflects the solar radiation at $0.8 \mu \mathrm{m}(10$ $15 \%)$ and absorbs the solar radiation at $1.6 \mu \mathrm{m}(50-60 \%)$ and $3.9 \mu \mathrm{m}(0-5 \%)$. The fog or stratus just north of the snow (lines 3390-3404) highly reflects the radiation at all the solar channels, indicating small droplets. 
Table A1. Values for the central wave number $v_{c}$ (in $\mathrm{cm}^{-1}$ ), and the parameters $\mathrm{A}$, and $\mathrm{B}$ (in $\mathrm{K}$ ) for the analytic relationship between radiance and equivalent brightness temperature for the thermal IR SEVIRI channels on MSG-1. Full description of the "Effective Radiance and Brightness Temperature Relation for Meteosat 8 and 9" can be found in http://www.eumetsat.int/Home/Main/ Access_to_Data/Meteosat_Image_Services/SP_1123237865326.

\begin{tabular}{ccccc}
\hline Channel No. & Channel ID & $v_{c}$ & $\mathrm{~A}$ & $\mathrm{~B}$ \\
\hline 04 & IR3.9 & 2569.094 & 0.9959 & 3.471 \\
05 & WV6.2 & 1598.566 & 0.9963 & 2.219 \\
06 & WV7.3 & 1362.142 & 0.9991 & 0.485 \\
07 & IR8.7 & 1149.083 & 0.9996 & 0.181 \\
08 & IR9.7 & 1034.345 & 0.9999 & 0.060 \\
09 & IR10.8 & 930.659 & 0.9983 & 0.627 \\
10 & IR12.0 & 839.661 & 0.9988 & 0.397 \\
11 & IR13.4 & 752.381 & 0.9981 & 0.576 \\
\hline
\end{tabular}

The brightness temperature $(T)$ is calculated using the inverse Planck function:

$T=\frac{\left(\frac{C_{2} v_{c}}{\ln \left(\frac{C_{1} v_{c}^{3}}{B}+1\right)}-b\right)}{a}$

The solar reflectance $(\rho)$ in channels $0.6,0.8$ and $1.6 \mu \mathrm{m}$ is calculated using Eq. (A4):

$\rho_{\lambda}=\frac{B_{\lambda}}{\mu_{0} F_{0}(\lambda)}$,

where $\mu_{0}$ is the cosine of the solar zenith angle $(\Theta) \Theta$ is calculated from the date, time, latitude and longitude of the pixel. For twilight condition, i.e. $\Theta>\Theta_{\max }, \Theta$ is set to $\Theta_{\max }$ to avoid $\mu_{0}$ from going to infinity. $\Theta_{\max }$ is set by default to $80^{\circ}$, but can be changed by the user. $F_{0}(\lambda)$ is the extraterrestrial solar flux at wavelength $\lambda$ [in $\mathrm{mW} \mathrm{m}^{-2}$ ster $^{-1}$ $\left(\mathrm{cm}^{-1}\right)^{-1}$ ]:

$F_{0}(\lambda)=\frac{\bar{F}_{0}(\lambda)}{\mathrm{ESD}^{2}}$

where the extraterrestrial solar flux at the equinox $\left(\bar{F}_{0}\right)$ at channels 1-4 is given in Table A2, and ESD is the earth-sundistance in Astronomical Units. ESD varies during the year according to Eq. (A6):

$\operatorname{ESD}(\mathrm{JD})=1-0.0167 \cos \left(\frac{2 \pi(\mathrm{JD}-3)}{365}\right)$

where JD is the Julian Day.

\section{A2 Special treatment of channel $4(3.9 \mu \mathrm{m})$}

The cloud reflectance in the $3.9 \mu \mathrm{m}$ channel $\left(\rho_{3.9}\right)$ was computed assuming that the emissivity of clouds in the IR
Table A2. The extraterrestrial solar flux at the equinox $\left(\bar{F}_{0}\right)$ at channels $1-4$ for MSG1 and MSG2. The wavelength $(\lambda)$ is in microns, and the solar flux in $\mathrm{mW} \mathrm{m}^{-2} \mathrm{ster}^{-1}\left(\mathrm{~cm}^{-1}\right)^{-1}$. From radiances to reflectances for SEVIRI warm channels: http://www. eumetsat.int/idcplg?IdcService=GET_FILE\&dDocName=pdf_ msg_seviri_rad2refl\&RevisionSelectionMethod=LatestReleased.

\begin{tabular}{ccccc}
\hline$\lambda$ & 0.6 & 0.8 & 1.6 & 3.9 \\
MSG1 & 20.76 & 23.24 & 19.85 & 4.92 \\
MSG2 & 20.76 & 23.30 & 19.73 & 4.92 \\
\hline
\end{tabular}

$(10.8 \mu \mathrm{m})$ is equal to 1.0 , and that the transmission through a cloud in the $3.9 \mu \mathrm{m}$ channel is zero (Rosenfeld et al., 2004).

Following Kaufman and Nakajima (1993), the total radiance at $3.9 \mu \mathrm{m}\left(L_{3.9}\right)$ and $10.8 \mu \mathrm{m}\left(L_{10.8}\right)$ is

$$
\begin{aligned}
& L_{3.9}=t_{3.9}^{0} F_{0}(3.9) \mu_{0} \rho_{3.9}+t_{3.9}^{\prime} B_{3.9}(T)\left(1-\rho_{3.9}\right), \\
& L_{10.8}=t_{10.8}^{\prime} B_{10.8}(T),
\end{aligned}
$$

where $B_{i}(T)$ is the Planck function for temperature $T$ and wavelength $i, t_{i}^{\prime}$ is the upward transmission of radiation above the cloud at wavelength $i$, and $t_{3.9}^{o}$ is the total downward and then upward transmission of radiation above the cloud at the $3.9 \mu \mathrm{m}$ channel. $\rho_{3.9}$ can be derived from Eqs. (A7) and (A8):

$\rho_{3.9}=\frac{L_{3.9}-t_{3.9}^{\prime} B_{3.9}(T)}{t_{3.9}^{0} F_{0}(3.9) \mu_{0}-t_{3.9}^{\prime} B_{3.9}(T)}$,

where

$T=\frac{B_{10.8}^{-1}\left(L_{10.8}\right)}{t_{10.8}^{\prime}}$

$t_{3.9}^{\prime}$ and $t_{3.9}^{o}$ depends on the $\mathrm{CO}_{2}$ and $\mathrm{H}_{2} \mathrm{O}$ absorption.

The 10.8 and $13.4 \mu \mathrm{m}$ channels brightness temperatures ( $T_{10.8}$ and $T_{13.4}$ respectively) were used to estimate the upward transmission of radiation above the cloud at the $13.4 \mu \mathrm{m}$ channel $\left(t_{13.4}^{\prime}\right)$ :

$t_{13.4}^{\prime}=\left(\frac{T_{13.4}}{T_{10.8}}\right)^{4}$,

The absorption at the $13.4 \mu \mathrm{m}$ channel is: $a_{13.4}^{\prime}=1-t_{13.4}^{\prime}$.

$\mathrm{CO}_{2}$ absorption is stronger in the $13.4 \mu \mathrm{m}$ channel then in the $3.9 \mu \mathrm{m}$ channel $\left(a_{13.4}^{\prime}>a_{3.9}^{\prime}\right)$. An empirical parameter $\alpha=0.8$ was chosen to 'correct' the $\mathrm{CO}_{2}$ limb cooling in the $3.9 \mu \mathrm{m}$ channel at nighttime so that $T_{3.9}=\mathrm{SST}$ (Sea Surface Temperature) in different satellite viewing angles.

$a_{3.9}^{\prime}=\alpha \cdot a_{13.4}^{\prime}$.

Lensky and Rosenfeld (2003a, b) used the brightness temperature difference between the 3.7 and $10.8 \mu \mathrm{m}$ channels $\left(\mathrm{BTD}_{3.7-10.8}\right)$ to infer cloud microphysics at nighttime. They 

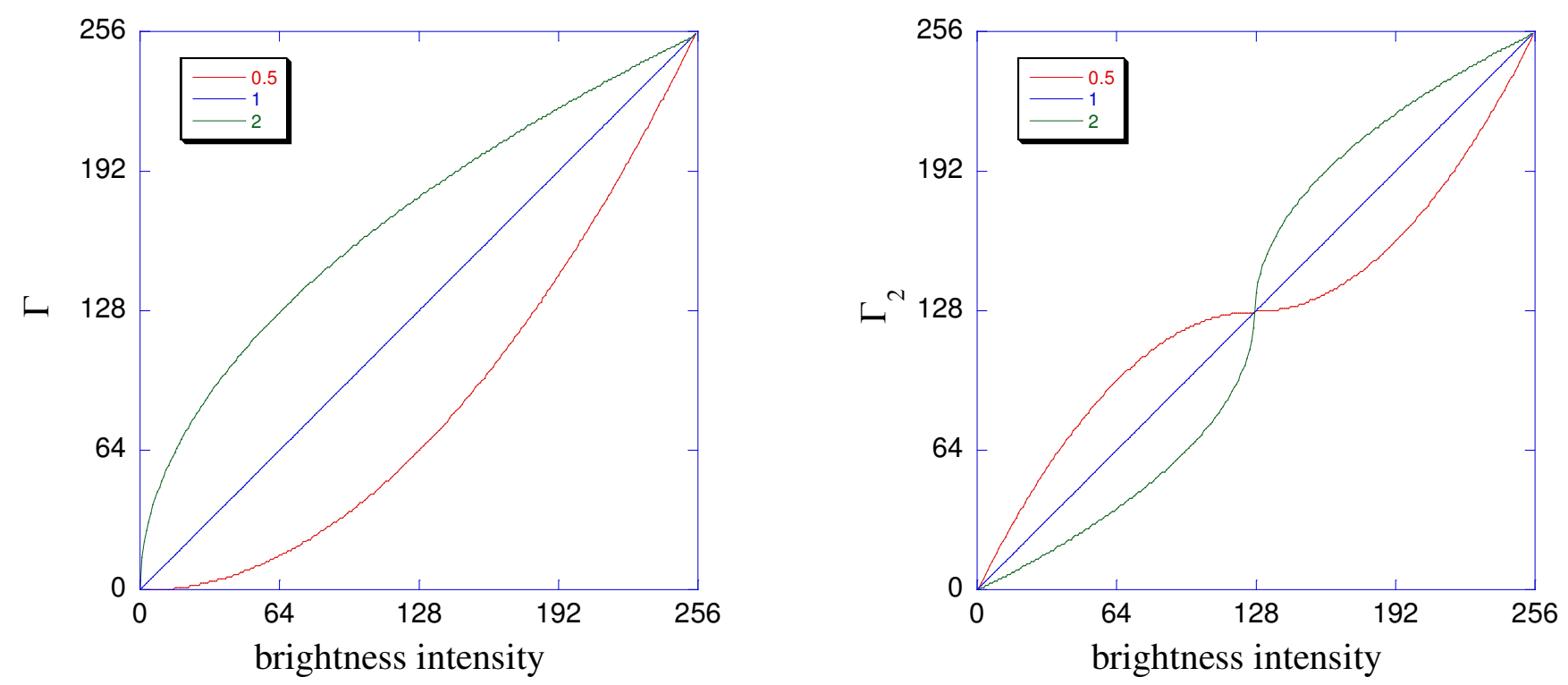

Fig. B1. $\Gamma$ and $\Gamma_{2}$ functions, used to change the dynamic range of an image.

also used $\mathrm{BTD}_{3.7-10.8}$ to delineate precipitation from clouds with warm tops. Therefore this "correction" is important for the retrieval of the cloud microphysics at the thermal channels, and is used in several color schemes.

The reflectance from the atmosphere of the emitted thermal radiation from cloud top at the $3.9 \mu \mathrm{m}$ channel is assumed to be negligible $\left(r_{3.9}^{\prime}=0\right)$, therefore the transmittance at nighttime is:

$t_{3.9}^{\prime}=1-a_{3.9}^{\prime}$.

Finally, $t_{3.9}^{o}$ can be estimated from:

$t_{3.9}^{0}=e^{-\left(a_{3.9}^{\prime}\right)} \cdot e^{-\left(a_{3.9}^{\prime} \frac{\mu}{\mu_{0}}\right)} \cdot e^{-\left(\frac{P W}{P W_{S}} \frac{a_{S}}{\mu \cdot \mu_{0}}\right)}$,

where $\mu$ is the cosine of the satellite zenith angle.

The first term in Eq. (A13) is the $\mathrm{CO}_{2}$ transmittance from cloud top to the satellite (calculated using $T_{10.8}, T_{13.4}$ and $\alpha$ ), the second term is the weighted $\left(\mu / \mu_{0}\right)$ transmittance from sun to cloud top, and the third term is the water vapor absorption, adapted from Rosenfeld and Lensky (1998). We assume that water vapor absorption is more or less the same in $T_{10.8}$ and $T_{13.4}$, therefore $a_{3.9}^{\prime}$ is not effected by the water vapor, so it has to be taken into account explicitly using the third term in Eq. (A13).

\section{Appendix B}

\section{$\Gamma_{2}$ enhancement}

Enhancement is used to change the dynamic range of an image. The $\Gamma$ correction is used to enhance the high (or low) brightness intensity (0-255) pixel values (BRIT) see Fig. B1.
$\Gamma_{2}$ correction is a $\Gamma$ function operated double sided from the middle of the intensity range. It is used to enhance the middle (or high and low) parts of the selected intensity range. The larger it is the more stretching is on the middle value at the expense of the extremes. For example, the formula to perform a $\Gamma_{2}$ correction on a IR brightness temperature $(T)$ image, within a range of $T_{\min }$ and $T_{\max }$ (see Table 1) is given in Eq. (B1):

BRIT $=\left\{\begin{array}{ll}128-128\left(\frac{\bar{T}-T}{\bar{T}-T_{\min }}\right)^{1 / \Gamma_{2}} & \text { for } T<\bar{T} \\ 128+128\left(\frac{T-\bar{T}}{T_{\max }-\bar{T}}\right)^{1 / \Gamma_{2}} & \text { for } T \geq \bar{T}\end{array}\right.$,

where $\bar{T}=\frac{T_{\min }+T_{\max }}{2}$.

Acknowledgements. The authors thank EUMETSAT for the support in developing the CAPSAT tool, Jochen Kerkmann for helpful discussions and for the data. The contribution of the second author to this study was also partially supported by EUCAARI (European integrated project on aerosol cloud climate and air quality interactions), funded by the European Union.

Edited by: D. Cziczo

\section{References}

Freud, E., Rosenfeld, D., Andreae, M. O., Costa, A. A., and Artaxo, P.: Robust relations between $\mathrm{CCN}$ and the vertical evolution of cloud drop size distribution in deep convective clouds, Atmos. Chem. Phys., 8, 1661-1675, 2008, http://www.atmos-chem-phys.net/8/1661/2008/.

Fromm, M., Tupper, A., Rosenfeld, D., Servranckx, R., and McRae, R.: Violent pyro-convective storm devastates Australia's capi- 
tal and pollutes stratosphere, Geophys. Res. Lett., 33, L05815, doi:10.1029/2005GL025161, 2006.

Inoue, T.: An instantaneous delineation of convective rainfall areas using split window data of NOAA-7 AVHRR, J. Meteor. Soc. Japan, 65, 469-481, 1987.

Lensky, I. M. and Drori, R.: A Satellite Based Parameter to Monitor the Aerosol Impact on Convective Clouds, J. Appl. Meteor. Clim., 45, 660-666, 2007.

Lensky, I. M. and Rosenfeld, D.: Satellite-based insights into precipitation formation processes in continental and maritime convective clouds at nighttime, J. Appl. Meteor., 42, 1227-1233, 2003a.

Lensky, I. M. and Rosenfeld, D.: A night rain delineation algorithm for infrared satellite data based on microphysical considerations, J. Appl. Meteor., 42, 1218-1226, 2003b.

Lensky, I. M. and Rosenfeld, D.: The time-space exchangeability of satellite retrieved relations between cloud top temperature and particle effective radius, Atmos. Chem. Phys., 6, 2887-2894, 2006 , http://www.atmos-chem-phys.net/6/2887/2006/.

Ricchiazzi, P., Yang, S., Gautier, C., and Sowle, D.: SBDART: A research and teaching software tool for plane parallel radiative transfer in the earth's atmosphere, B. Am. Meteorol. Soc., 79, 2101-2114, 1998.

Rosenfeld, D. and Lensky, I. M.: Satellite-based insights into precipitation formation processes in continental and maritime convective clouds, B. Am. Meteorol. Soc., 79, 2457-2476, 1998.

Rosenfeld, D.: TRMM observed first direct evidence of smoke from forest fires inhibiting rainfall, Geophys, Res. Lett., 26, 31053108, 1999.

Rosenfeld, D.: Suppression of rain and snow by urban and industrial air pollution, Science, 287, 1793-1796, 2000.

Rosenfeld, D., Rudich, Y., and Lahav, R.: Desert dust suppressing: A possible desertification feedback loop, Proc. Natl. Acad. Sci. USA, 98, 5975-5980, 2001.

Rosenfeld, D., Lahav, R., Khain, A. P., and Pinsky, M.: The role of sea-spray in cleansing air pollution over ocean via cloud processes, Science, 297, 1667-1670, 2002.

Rosenfeld, D., Cattani, E., Melani, S., and Levizzani, V.: Considerations on daylight operation of $1.6 \mu \mathrm{m}$ vs $3.7 \mu \mathrm{m}$ channel on NOAA and METOP Satellites, B. Am. Meteorol. Soc., 85, 873881, 2004.

Rosenfeld, D. and Woodley, W. L.: Closing the 50-year circle: From cloud seeding to space and back to climate change through precipitation physics, Chapter 6 of Cloud Systems, Hurricanes, and the Tropical Rainfall Measuring Mission (TRMM), edited by: Tao, W.-K. and Adler, R., 234 pp., p. 59-80, Meteorological Monographs, 51, AMS, 2003.
Rosenfeld, D. and Woodley, W. L.: Pollution and Clouds, Physics, World, Institute of Physics Publishing LTD, Dirac House, Temple Back, Bristol BS1 6BE, UK, February 2001, 33-37, 2001.

Rosenfeld, D., Lensky, I. M., Peterson, J., and Gingis, A.: Potential impacts of air pollution aerosols on precipitation in Australia, Clean Air and Environmental Quality, 41, 43-49, 2006.

Rosenfeld, D., Woodley, W. L., Krauss, T. W., and Makitov, V.: Aircraft Microphysical Documentation from Cloud Base to Anvils of Hailstorm Feeder Clouds in Argentina, J. Appl. Meteor., 45, 1261-1281, 2006.

Rosenfeld, D., Fromm, M., Trentmann, J., Luderer, G., Andreae, M. O., and Servranckx, R.: The Chisholm firestorm: observed microstructure, precipitation and lightning activity of a pyrocumulonimbus, Atmos. Chem. Phys., 7, 645-659, 2007, http://www.atmos-chem-phys.net/7/645/2007/.

Ramanathan, V., Crutzen, P. J., Kiehl, J. T., and Rosenfeld, D.: Aerosols, Climate and the Hydrological Cycle, Science, 294, 2119-2124, 2001.

Rudich, Y., Rosenfeld, D., and Khersonsky, O.: Treating clouds with a grain of salt, Geophys. Res. Lett., 29(22), 2060, doi:10.1029/2002GL016055, 2002.

Rudich, Y., Sagi, A., and Rosenfeld, D.: Influence of the Kuwait oil fires plume (1991) on the microphysical development of clouds, J. Geophys. Res., 108(D15), 4478, doi:10.1029/2003JD003472, 2003.

Schmetz, J., Pili, P., Tjemkes, S., Just, D., Kerkmann, J., Rota, S., and Ratier, A.: An Introduction to Meteosat Second Generation (MSG), B. Am. Meteorol. Soc., 83, 977-992, 2002.

Tupper, A., Oswalt, J. S., and Rosenfeld, D.: Satellite and radar analysis of the 'volcanic' thunderstorms at $\mathrm{Mt}$ Pinatubo, Philippines, 1991, J. Geophys. Res., 110, D09204, doi:10.1029/2004JD005499, 2004.

Vanderlei Martins, J., Marshak, A., Remer, L. A., Rosenfeld, D., Kaufman, Y. J., Fernandez-Borda, R., Koren, I., Zubko, V., and Artaxo, P.: Remote sensing the vertical profile of cloud droplet effective radius, thermodynamic phase, and temperature, Atmos. Chem. Phys. Discuss., 7, 4481-4519, 2007, http://www.atmos-chem-phys-discuss.net/7/4481/2007/.

Williams, E., Rosenfeld, D., and Madden, M.: Contrasting convective regimes over the Amazon: Implications for cloud electrification, J. Geophys. Res., 107(D20), 8082, doi:10.1029/2001JD000380, 2002.

Woodley, W. L., Rosenfeld, D., and Strautins, A.: Identification of a seeding signature in Texas using multi-spectral satellite imagery, J. Wea. Mod., 32, 37-52, 2000. 